\title{
HOSPITAL-RELATED DETERMINANTS FOR SURGICAL-SITE INFECTION FOLLOWING HIP ARTHROPLASTY
}

Eveline L. P. E. Geubbels, PhD; Jan C. Wille; Nico J. D. Nagelkerke, PhD; Christina M. J. E. Vandenbroucke-Grauls, MD, PhD; Diederick E. Grobbee, MD, PhD; Annette S. de Boer, PhD

\begin{abstract}
OBJECTIVE: To determine hospital-related risk factors for surgical-site infection (SSI) following hip arthroplasty.

DESIGN: Prospective, multicenter cohort study based on surveillance data and data collected through a structured telephone interview. With the use of multilevel logistic regression, the independent effect of hospital-related characteristics on SSI was assessed.

SETTING: Thirty-six acute care hospitals in the Dutch surveillance network for nosocomial infections (PREZIES), from 1996 to 2000.

PATIENTS: Thirteen thousand six hundred eighty patients who underwent total or partial hip arthroplasty.

RESULTS: A high annual volume of operations was as-
\end{abstract}

sociated with a reduced risk of SSI (risk-adjusted risk ratio [RR] per 50 extra operations, $0.85 ; 95 \%$ confidence interval $\left[\mathrm{CI}_{95}\right]$, $0.74-0.97)$. With each extra full-time-equivalent infection control staff member per 250 beds available for prevention of SSI, the risk for SSI was decreased ( $\left.\mathrm{RR}, 0.48 ; \mathrm{CI}_{95}, 0.16-1.44\right)$, although the decrease was not statistically significant. Hospital size, teaching status, university affiliation, and number of surgeons and their years of experience showed no important association with the risk of SSI.

CONCLUSION: Undergoing surgery in a hospital with a low volume of operations increases a patient's risk of SSI (Infect Control Hosp Epidemiol 2005;26:435-441).
Surgical-site infections (SSIs) are a common complication of surgery and occur after both clean and contaminated procedures. ${ }^{1}$ They prolong the hospital stay on average by 8 days, double the risk of death, and are associated with a fivefold higher risk of readmission. ${ }^{2}$ Insight into variables that influence the risk of SSI is important for two reasons.

First, they can indicate how or in which patient populations a reduction in SSI risk might be achieved. For example, because preoperative shaving is associated with a higher risk of SSI, abolishment of this practice may prevent SSI. ${ }^{3}$ Likewise, because patients with remote infections are at increased risk of SSI, these infections are best treated before surgery is performed. ${ }^{3}$

Second, knowledge about risk factors for SSI is needed to compare the incidence of SSI among surgeons and among hospitals or, in time, to detect potential quality problems in preoperative, perioperative, or postoperative care. ${ }^{4-6}$ For the comparison of SSI rates to provide insight into differences in quality of care, these rates must be adjusted for the patient's intrinsic, or nonmodifiable, risk of SSI.

Many authors have investigated the relative importance of patient-related and procedure-related characteristics, ${ }^{7}$ and several risk indices have been constructed to adjust

Drs. Geubbels and de Boer are from the Department of Infectious Diseases Epidemiology and Dr. Nagelkerke is from the Department of Computerization and Methodological Consultancy, National Institute of Public Health and the Environment (RIVM), Bilthoven, the Netherlands. Mr. Wille is from the Dutch Institute for Healthcare Improvement CBO, Utrecht, the Netherlands. Dr. Vandenbroucke-Grauls is from the Department of Medical Microbiology and Infection Control, Vrije Universiteit Medical Center, Amsterdam, the Netherlands. Dr. Grobbee is from the Julius Center for Health Sciences and Primary Care, University Medical Center Utrecht, Utrecht, the Netherlands.

Address reprint requests to J. C. Wille, Dutch Institute for Healthcare Improvement CBO, PO Box 20064, 3502 LB, Utrecht, the Netherlands. j.wille@cbo.nl

Supported by the Ministry of Health, Welfare, and Sports, The Hague, the Netherlands.

The authors thank the infection control professionals, medical specialists, and nurses of the following hospitals for their contributions to the data collection: 't Lange Land Hospital, Zoetermeer; Albert Schweitzer Hospital at Amstelwijck, Dordrecht; Albert Schweitzer Hospital at Dordwijck, Dordrecht; Albert Schweitzer Hospital at Zwijndrecht, Zwijndrecht; Beatrix Hospital, Gorinchem; Bernhoven Hospital at St. Anna, Oss; Bosch Medicenter, Den Bosch; BovenIJ Hospital, Amsterdam; Catharina Hospital, Eindhoven; Deventer Hospitals Group, Deventer; Elkerliek Hospital, Helmond; Groene Hart Hospital, Gouda; Harbor Hospital, Rotterdam; Hospital De Gelderse Vallei at Bennekom, Bennekom; Hospital Hilversum, Hilversum; Hospital Nij Smellinghe, Drachten; Hospital Rivierenland, Tiel; Hospital Walcheren, Vlissingen; Isala Hospitals at Weezenlanden, Zwolle; Isala Hospitals at Sophia, Zwolle; Leiden University Hospital, Leiden; Medical Center Molendael, Baarn; Medical Center Leeuwarden South, Leeuwarden; Medical Spectrum Twente at Oldenzaal, Oldenzaal; Oosterschelde Hospitals Group, Goes; Regional Hospital Coevorden-Hardenberg, Coevorden; Regional Hospital Queen Beatrix, Winterswijk; Regional Hospital Zevenaar, Zevenaar; St. Carolus Liduina Hospital, Den Bosch; St. Elisabeth Hospital, Tilburg; St. Franciscus Hospital, Rotterdam; University Hospital Groningen, Groningen; University Hospital Maastricht, Maastricht; Vlietland Hospital at Schieland, Schiedam; Vlietland Hospital at Holy, Vlaardingen; Wilhelmina Hospital, Assen; and Zuider Hospital, Rotterdam. They also thank Dr. J. Mintjes-de Groot, Dr. J. Keeman, and Dr. G. Walenkamp for their valuable comments during the planning of the study.

Presented at the 12th Annual Meeting of the Society for Healthcare Epidemiology of America; April 6-9, 2002; Salt Lake City, UT. 
for intrinsic patient or procedure risk. ${ }^{4}$ Some authors also have reported hospital-related or surgeon-related characteristics to be associated with SSI or other nosocomial infections. Examples are size and teaching status of the hospital, the annual number of operations performed in the hospital or by a surgeon, the experience of the surgeon, the amount of personnel available for prevention of infection, and feedback of surgeon-specific infection rates. ${ }^{8-12}$ It is often unclear, however, whether these factors are associated with SSI independent of patient-related and procedure-related characteristics or other hospital-related characteristics. Except for the Study on the Efficacy of Nosocomial Infection Control (SENIC) performed in the $1970 \mathrm{~s},{ }^{8}$ the majority of these studies either were based on only one or a few hospitals or did not provide detailed information suitable for adjustment for patient-related, procedure-related, and other hospital-related factors. The Dutch Network for Prevention of Nosocomial Infections Through Surveillance (PREZIES) does provide these data. ${ }^{1}$ Since its start in 1996, approximately $60 \%$ of all Dutch hospitals providing surgical services have participated in the network, which is coordinated by the Dutch Institute for Healthcare Improvement CBO and the National Institute of Public Health and the Environment. In this cohort study, conducted in the PREZIES network, we aimed to determine whether there was an independent association between hospital-related factors and the risk of SSI.

\section{METHODS \\ Setting}

This study was performed within the Dutch PREZIES surveillance network for SSI. Participation in this network is open to all hospitals in the country that provide surgical services. Hospitals were invited to take part in this study in June 1996. Data regarding operations were collected prospectively from January 1, 1996, through December 31, 2000. Data from the first half of 1996 came from the pilot study of the PREZIES network, but methods for data collection remained the same throughout the study period. Data regarding hospital-related determinants were collected during a single, structured telephone interview of personnel at each participating hospital. The Netherlands has a healthcare system in which patients are usually seen first by their own general practitioner, who can refer them for specialized treatment (eg, elective surgery) in the hospital. Casualties present directly to the hospital. The majority of Dutch hospitals are government-owned general hospitals that provide a broad range of clinical specialties such as surgery (general, orthopedic, eye, or ear, nose, and throat), obstetrics and gynecology, pediatrics, internal medicine, accident and emergency medicine, and all supporting diagnostic disciplines. The sizes of the hospitals ranged from 60 to 1,307 beds; $70 \%$ had more than 300 beds. Approximately $60 \%$ of all hospitals that provide surgical services in the Netherlands have participated in the PREZIES network. These include university-affiliated teaching hospitals, regional teaching hospitals, and non-teaching hospitals from all over the country. Large hospitals (> 600 beds) are slightly overrepresented.
The surveillance methods of the PREZIES network have been described previously. ${ }^{1}$ Infection control professionals in hospitals performed active, prospective, in-hospital surveillance, according to a standardized protocol, using the Centers for Disease Control and Prevention definitions for SSI. ${ }^{13,14}$ According to these criteria, an SSI is defined as nosocomial if it occurs within 30 days postoperatively. If a prosthetic device is implanted, this period is extended to 1 year postoperatively. Data were entered into computer software in the hospitals and sent to the national center, where they were analyzed. Regular feedback reports were sent to the hospitals. Participation of hospitals in the PREZIES network is voluntary and confidential and can start at any time. Hospitals in the PREZIES network are free to choose the types of procedures included in the surveillance. This allows them to tailor the national surveillance system to their own needs. To ensure meaningful comparison with other hospitals' rates, the feedback they receive is procedure specific.

\section{Study Population}

To provide enough power to determine the independent association of hospital-related factors with the risk of SSI, the study was limited to the procedure that was most commonly included, which was hip arthroplasty (both total hip replacements and replacements of the head of the femur). Hospitals were excluded if they had not included hip arthroplasties in their surveillance system or had stopped performing surveillance before January 1, 1999. Forty-nine hospitals met the inclusion criteria, and 36 agreed to participate in the study $(73.5 \%)$ providing data from 1996 through 2000. Ten hospitals declined because of lack of time, two because they had stopped collecting surveillance data at the time of the invitation, and one because its surgeons refused. These 36 hospitals collected data on 13,680 operations, after which 458 SSIs occurred.

\section{Data Collection}

Data about possible hospital-related determinants of SSI were collected during the first trimester of 2000 through structured telephone interviews with the infection control professional responsible for SSI surveillance. The interview contained questions about the number of beds, university affiliation, annual volume of operations per selected procedure, and total number of full-time-equivalent infection control staff available and number available for the prevention of SSI specifically. Information was collected about teaching status, whether residents in teaching hospitals were allowed to perform the selected procedures without supervision, and the number of orthopedic surgeons and their years of experience. From the latter, the median number of years of surgeon experience was calculated for each of the departments. These data about hospital-related characteristics were taken as a proxy for their values during the whole study period.

Data about possible patient-related and procedurerelated confounders for the association between hospitalrelated determinants and SSI were collected prospectively 
by the infection control professional for each patient under surveillance. These possible confounders were age, American Society of Anesthesiologists score, ${ }^{15}$ wound contamination class ${ }^{16}$ duration of preoperative stay in the hospital, type of procedure, duration of surgery, and whether the surgery was elective or emergent. Postdischarge surveillance was performed with the use of a registration card to be completed for each patient by the surgeon. Complementary postdischarge chart review by the infection control professional was recommended but not required. However, because use of postdischarge surveillance was found to not influence the relative risk of infection associated with size, teaching status, annual volume of surgery, or other hospital characteristics (Appendix), we did not include it as a confounder in the analysis. Teaching status was considered a possible confounder for all determinants except university affiliation. The number of surgeons was regarded as a potential confounding factor for the annual volume of operations and for the surgeons' median number of years of experience. The total number of infection control staff was considered a possible predictor of the prevention of SSI.

\section{Data Analysis}

We generated box-and-whisker plots to describe the distribution of hospitals' SSI rates for the two procedures. The boxes present the average and mean of all hospital rates plus the 25 th and 75 th percentiles. Whiskers extend to the maximum and minimum SSI rates.

To determine the association of hospital-related factors with SSI adjusted for confounding, the hierarchical structure of the data had to be taken into account. From a statistical point of view, operations can be regarded as firstlevel units of observation that are clustered within the second-level units, hospitals. Therefore, we applied multilevel modeling to assess both the crude and the adjusted association of hospital-related factors with the occurrence of SSI. We used MLWiN software (release 1.10.0006; Multilevel Models Project, Institute of Education, University of London, London, United Kingdom) for the multilevel modeling and SAS software (release 6.12 for Windows; SAS Institute, Inc., Cary, NC) for all other analyses.

The following strategy was used. ${ }^{17}$ Crude risk ratios (RRs) and 95\% confidence intervals $\left(\mathrm{CI}_{95}\right)$ were calculated for all eight potential determinants with multilevel logistic regression. For determinants that were measured at a procedure-specific level (eg, annual volume of operations), these crude models also included variables indicating the type of procedure. The adjusted association was then assessed by stepwise inclusion of possible confounders (ie, patientrelated and procedure-related characteristics and, depending on the determinant, hospital-related characteristics). A factor was considered a confounder if it changed the estimate of the determinant by more than $10 \%$ of its last value. The maximum number of hospital-related variables to be included in a model was restricted to four because of the limited number of hospitals in the study. For the comparison of the goodness of fit of two consecutive models, the Wald test was used. ${ }^{18}$

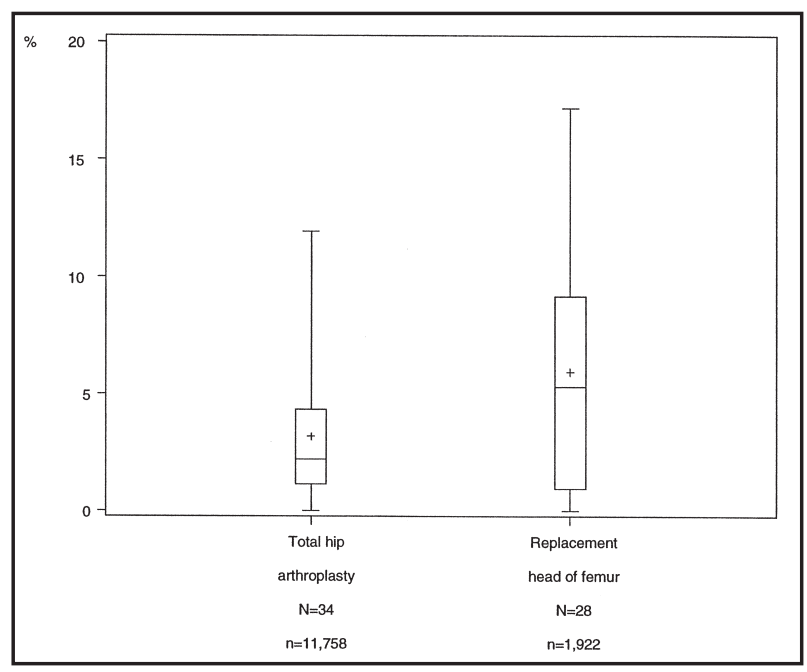

FIGURE. Box-and-whisker plots of the distribution of hospitals' surgicalsite infection (SSI) rates per type of procedure. $\mathrm{N}=$ number of hospitals; $\mathrm{n}=$ number of operations; line inside of the box = median SSI rate; $+=$ mean; upper and lower edges of the box $=75$ th and 25 th percentiles, respectively; and whiskers = maximum and minimum SSI rates.

\section{RESULTS \\ Incidence of SSI and Description of the Population}

The distribution of hospital SSI rates per type of procedure is presented in the figure. The median of the hospitals' infection rates was $2.2 \%$ for total hip arthroplasties and $5.3 \%$ for replacements of the head of the femur. One-fifth of all infections were detected after discharge. Table 1 lists the patient-related and procedurerelated characteristics for these operations. As could be expected for these procedures, the majority of patients were relatively healthy, and few were admitted to the hospital for more than 3 days preoperatively. The procedure characteristics revealed that the selected operations were primarily clean and elective. The distribution of hospital-related determinants is presented in Table 2. Approximately half of the hospitals were of intermediate size (300 to 600 beds). Approximately half were also teaching hospitals, but most were not affiliated with a university. The number of surgeons, their median number of years of experience, and the annual volume of operations showed wide variation between hospitals. As a median, almost 1 full-time-equivalent employee per 250 beds was available for infection control and prevention, of which one-sixth was devoted to SSIs, but these figures also varied substantially among the hospitals.

\section{Risk Factors Associated With SSI}

The results of the multilevel logistic modeling are presented in Table 3 . RRs with $\mathrm{CI}_{95}$ are given for both the crude and the adjusted association of each hospital-related determinant with SSI.

Undergoing a hip arthroplasty in a hospital with a higher annual volume of operations was the only studied 
TABLE 1

PATIENT AND PROCEDURE CHARACTERISTICS FOR 13,680 HIP ARTHROPLASTIES PERFORMED IN 36 HOSPITALS

\begin{tabular}{|c|c|}
\hline Characteristic & $\%$ of Operations* \\
\hline \multicolumn{2}{|l|}{ Patients } \\
\hline \multicolumn{2}{|l|}{ Age, y } \\
\hline$<45$ & 2.2 \\
\hline 45 to 64 & 23.4 \\
\hline 65 to 74 & 36.0 \\
\hline$\geqslant 75$ & 38.3 \\
\hline $\begin{array}{l}\text { No severe systemic underlying disease } \\
\text { (ASA score, } 1 \text { to } 2 \text { ) }\end{array}$ & 79.9 \\
\hline $\begin{array}{l}\text { Severe systemic underlying disease } \\
\text { (ASA score, } 3 \text { to 5) }\end{array}$ & 14.7 \\
\hline Severe systemic underlying disease not reported & 5.5 \\
\hline Preoperative hospital stay, 1 to $2 \mathrm{~d}$ & 93.5 \\
\hline Preoperative hospital stay, $\geqslant 3 \mathrm{~d}$ & 6.5 \\
\hline $\begin{array}{l}\text { Postdischarge surveillance according to } \\
\text { recommended method }\end{array}$ & 31.8 \\
\hline $\begin{array}{l}\text { Postdischarge surveillance according to other } \\
\text { method }\end{array}$ & 25.8 \\
\hline No postdischarge surveillance performed & 39.7 \\
\hline $\begin{array}{l}\text { Postdischarge surveillance performance not } \\
\text { reported }\end{array}$ & 2.7 \\
\hline \multicolumn{2}{|l|}{ Procedures } \\
\hline Replacement of head of femur & 14.1 \\
\hline Total hip prosthesis & 86.0 \\
\hline $\begin{array}{l}\text { Clean or clean-contaminated surgery } \\
\text { (wound class, } 1 \text { to } 2 \text { ) }\end{array}$ & 99.2 \\
\hline $\begin{array}{l}\text { Contaminated or dirty or infected surgery } \\
\text { (wound class, } 3 \text { to } 4 \text { ) }\end{array}$ & 0.3 \\
\hline Wound class not reported & 0.5 \\
\hline $\begin{array}{l}\text { Duration of surgery } \leqslant \text { procedure-specific } 75 \text { th } \\
\text { percentile }^{\dagger}\end{array}$ & 74.9 \\
\hline $\begin{array}{l}\text { Duration of surgery > procedure-specific } 75 \text { th } \\
\text { percentile }^{\dagger}\end{array}$ & 24.7 \\
\hline Duration of surgery not reported & 0.4 \\
\hline Planned surgery & 89.9 \\
\hline Emergency surgery & 10.1 \\
\hline Type of surgery not reported & 0.1 \\
\hline
\end{tabular}

ASA $=$ American Society of Anesthesiologists

*Percentages have been rounded and may not always add up to $100 \%$.

${ }^{\dagger}$ Ninety minutes for replacement of head of femur and 105 minutes for total hip prosthesis.

variable associated with a significantly reduced risk of SSI (RR per 50 extra operations, $0.85 ; \mathrm{CI}_{95}, 0.74$ to 0.97 ). Hospital size, university affiliation, and the number of surgeons and their number of years of experience did not greatly influence the risk for SSI.
TABLE 2

DISTRIBUTION OF CATEGORICAL AND CONTINUOUS

HOSPITAL-RELATED VARIABLES FOR 36 HOSPITALS

PERFORMING HIP ARTHROPLASTY

\begin{tabular}{lcc}
\hline $\begin{array}{l}\text { Hospital-Related } \\
\text { Determinant }\end{array}$ & $\begin{array}{c}\text { No. (\%) of } \\
\text { Hospitals }\end{array}$ & $\begin{array}{c}\text { (10th Percentile, } \\
\text { 90th Percentile) }\end{array}$ \\
\hline $\begin{array}{l}\text { No. of beds } \\
<300\end{array}$ & $10(27.8)$ & \\
300 to 600 & $17(47.2)$ & \\
$>600$ & $9(25.0)$ & \\
$\begin{array}{l}\text { Non-university -affiliated } \\
\text { hospital }\end{array}$ & $33(91.7)$ & \\
$\begin{array}{l}\text { University-affiliated hospital } \\
\text { Non-teaching hospital }\end{array}$ & $3(8.3)$ & \\
$\begin{array}{l}\text { Teaching hospital, residents } \\
\text { allowed to operate un- }\end{array}$ & $2(5.5)$ & \\
supervised & & \\
$\begin{array}{l}\text { Teaching hospital, residents } \\
\text { not allowed to operate un- } \\
\text { supervised }\end{array}$ & $15(41.7)$ & \\
Annual volume of operations \\
$\begin{array}{l}\text { Replacement of head of } \\
\text { femur }\end{array}$
\end{tabular}

\section{DISCUSSION}

We found that a higher number of surgeries performed reduced the risk of SSI for a hospital. This finding was not explained by risk factors related to patients or procedures or by other characteristics of the hospital.

To appreciate our findings, several issues need to be addressed. Bias may have occurred through the selection of hospitals because not all hospitals participating in the PREZIES network took part in this study. However, the distribution of procedure-specific infection rates of nonparticipating hospitals did not differ from that of hospitals in this study nor was the distribution of known hospital characteristics such as size and teaching status any 
TABLE 3

CRUDE AND ADJUSTED RISK RATIOS AND 95\% CONFIDENCE INTERVALS FOR ASSOCIATION OF HOSPITAL-RELATED DETERMINANTS AND SURGICAL-SITE INFECTION FOLLOWING HIP ARTHROPLASTIES

\begin{tabular}{|c|c|c|c|c|}
\hline \multirow[b]{2}{*}{ Hospital-Related Determinant } & \multicolumn{2}{|c|}{ Crude } & \multicolumn{2}{|c|}{ Adjusted } \\
\hline & $\mathbf{R R}$ & $\mathbf{C l}_{95}$ & $\mathbf{R R}$ & $\mathbf{C l}_{95}$ \\
\hline \multicolumn{5}{|l|}{ No. of beds } \\
\hline$<300$ & $1^{*}$ & & $1^{*}$ & \\
\hline 300 to 600 & 1.15 & $0.61-2.16$ & 1.26 & $0.71-2.22$ \\
\hline$>600$ & 0.81 & $0.39-1.66$ & 0.78 & $0.40-1.51^{\dagger}$ \\
\hline Non-university-affiliated hospital & $1^{*}$ & & $1^{*}$ & \\
\hline University-affiliated hospital & 1.39 & $0.53-3.59$ & 1.32 & $0.55-3.19^{\ddagger}$ \\
\hline Non-teaching hospital & $1^{*}$ & & $1^{*}$ & \\
\hline $\begin{array}{l}\text { Teaching hospital, residents allowed to operate without } \\
\text { supervision }\end{array}$ & 0.57 & $0.21-1.54$ & 0.60 & $0.23-1.54^{\ddagger}$ \\
\hline $\begin{array}{l}\text { Teaching hospital, residents not allowed to operate with- } \\
\text { out supervision }\end{array}$ & 1.23 & $0.79-1.90$ & 1.28 & $0.83-1.97^{\dagger}$ \\
\hline Annual volume of operations (per 50 operations) & 0.87 & $0.77-0.98$ & 0.85 & $0.74-0.97^{\dagger}$ \\
\hline $\begin{array}{l}\text { Staff for nosocomial infection prevention and control (per } \\
\text { full-time-equivalent employees per } 250 \text { beds) }\end{array}$ & 1.24 & $0.61-2.16$ & 1.21 & $0.64-2.30$ \\
\hline $\begin{array}{l}\text { Staff for prevention and control of SSIs (per full-time- } \\
\text { equivalent employees per } 250 \text { beds) }\end{array}$ & 0.60 & $0.17-2.11$ & 0.48 & $0.16-1.44^{\prime}$ \\
\hline No. of surgeons & 1.09 & $0.95-1.24$ & 1.08 & $0.92-1.25^{\S}$ \\
\hline Median no. of years of surgeons' experience (per 5 y) & 0.94 & $0.75-1.17$ & 0.98 & $0.79-1.21^{\dagger}$ \\
\hline \multicolumn{5}{|c|}{$\begin{array}{l}\mathrm{RR}=\text { risk ratio; } \mathrm{CI}_{95}=95 \% \text { confidence interval; } \mathrm{SSI}=\text { surgical-site infections. } \\
{ }^{*} \text { Reference category. } \\
{ }^{\circ} \text { Adjusted for characteristics of the patient (age, American Society of Anesthesiologists score, and duration of preoperative hospital stay) and the procedure (wound contamination class, type of surgery } \\
\text { duration of surgery, and whether surgery was elective or emergent) and for teaching status. } \\
\text { *Adjusted for characteristics of the patient and the procedure. }\end{array}$} \\
\hline
\end{tabular}

different (data not shown). We thus think it unlikely that the results were biased through selective participation of hospitals.

The cross-sectional measurement of the hospital characteristics may have biased our results. For several hospital characteristics (eg, experience and number of surgeons), changes might have occurred during the 5year period of collection of data on operations. But because the extent and direction of change was unlikely to be associated with high or low SSI rates, we do not believe that these changes affected the results. However, changes in manpower for prevention and control of SSI may well have been driven by either high or low infection rates in some hospitals (ie, we think that a hospital that found high SSI rates in the beginning of the surveillance was more likely to have increased rather than decreased the number of staff dedicated to SSI prevention and control in later years). Likewise, it is plausible that low starting rates did not lead a hospital to increase its surveillance and control activities in later years. We therefore think that if a change in manpower occurred during the surveillance period, its direction would have resulted in an underestimation of the protective effect.

We used multilevel logistic modeling, which is increasingly used in health research. ${ }^{19}$ The multilevel approach takes into account the hierarchical structure of the data, with patients clustered within hospitals. Because part of our data were measured at the hospital level and part at the patient level, multilevel modeling was more suitable for our analysis than traditional logistic regression. In addition, although we included several hospital characteristics as confounders, it is probable that cluster effects remain, as patients from the same hospital are subject to similar treatment policies. Ignoring this clustering would likely have resulted in an underestimation of the standard errors for the effect estimates.

Our observation that the risk of SSI was lower for high-volume hospitals confirms the results of a study by Farber and Wenzel. They found an inverse relationship between the surgical volume for procedures of low complexity (eg, colectomies and abdominal hysterectomies) and the incidence of postoperative wound infection for 22 U.S. hospitals. ${ }^{9}$ The SENIC investigators, who adjusted for severity of case mix, also found fewer SSIs with higher volume. ${ }^{8}$ A recent study did not detect a relationship between hospital volume and mortality rate in common operations (eg, colectomies and total hip arthroplasties), ${ }^{20}$ whereas others did report an effect for colon cancer surgery ${ }^{21}$ and for breast cancer surgery. ${ }^{22}$ For more complex operations, there is circumstantial evidence for an inverse relationship between volume and mortal- 
ity. ${ }^{23-26}$ This suggests that mortality is less sensitive than morbidity (SSI rate) to differences in hospital volume in procedures of low complexity.

Our finding of a lower risk of SSI with higher hospital volume may be the result of differences in the technical skills of individual surgeons. We were not able to investigate this, as individual surgeon data were not available. Still, other authors have shown that hospital volume is a stronger predictor of healthcare outcomes than individual surgeon volume. ${ }^{27}$ Because prevention of SSI involves a multidisciplinary approach, it is likely that variations in the proficiency of entire operating teams also underlie our results. Insight into the differences in the perioperative processes of these teams and sharing of best practices may be a valuable tool to achieve a reduction of SSI risk.

Patients undergoing surgery in a hospital with more infection control staff devoted to prevention and control of SSIs appeared to have a somewhat decreased risk of SSI, but this was not statistically significant. SENIC showed that establishing a strong surveillance and infection control program, including a system for feedback of SSI rates to surgeons, was essential for the prevention of SSIs. ${ }^{8}$ Because most of the activities that make up surveillance and control of SSI are the work of infection control staff, our finding that having more fulltime-equivalent infection control staff per 250 beds was associated with a trend toward lower risk of SSI seems plausible. In another study, we demonstrated that infection control capacity is well spent on SSI surveillance because a longer period of surveillance in hospitals substantially reduced the risk of SSI for their patients. ${ }^{28}$

Our study suggested that a low volume of surgery is associated with an increased risk of SSI for the patient undergoing hip arthroplasty, confirming the findings of previous studies. These findings may have implications for risk stratification of SSI rates that are used for comparison of hospitals or surgical teams. The reason for a reduced risk with a high hospital volume of operations deserves further study.

\section{REFERENCES}

1. Geubbels EL, Mintjes-de Groot AJ, van den Berg JM, de Boer AS. An operating surveillance system of surgical-site infections in the Netherlands: results of the PREZIES national surveillance network. Preventie van Ziekenhuisinfecties door Surveillance. Infect Control Hosp Epidemiol 2000;21:311-318.

2. Kirkland KB, Briggs JP, Trivette SL, Wilkinson WE, Sexton DJ. The impact of surgical-site infections in the 1990s: attributable mortality, excess length of hospitalization, and extra costs. Infect Control Hosp Epidemiol 1999;20:725-730.

3. Mangram AJ, Horan TC, Pearson ML, Silver LC, Jarvis WR. Guideline for prevention of surgical site infection, 1999: Hospital Infection Control Practices Advisory Committee. Infect Control Hosp Epidemiol 1999;20:250-280.

4. Haley RW. Measuring the intrinsic risk of wound infection in surgical patients. Problems in General Surgery 1993;10:396-417.

5. Roy MC, Perl TM. Basics of surgical-site infection surveillance. Infect Control Hosp Epidemiol 1997;18:659-668.

6. Lee TB, Baker OG, Lee JT, Scheckler WE, Steele L, Laxton CE. Recommended practices for surveillance: Association for Professionals in Infection Control and Epidemiology, Surveillance Initiative Working Group. Am J Infect Control 1998;26:277-288.

7. Wong ES. Surgical site infections. In: Mayhall CG, ed. Hospital Epidemiology and Infection Control. Baltimore: Williams \& Wilkins; 1996:154-175.

8. Haley RW, Culver DH, White JW, et al. The efficacy of infection surveillance and control programs in preventing nosocomial infections in US hospitals. Am J Epidemiol 1985;121:182-205.

9. Farber BF, Wenzel RP. Postoperative wound infection rates: results of prospective statewide surveillance. Am J Surg 1980;140:343346.

10. Lau WY, Fan ST, Chu KW, Yip WC, Yuen WC, Wong KK. Influence of surgeons' experience on postoperative sepsis. Am J Surg 1988;155:322-326.

11. Gastmeier P, Kampf G, Wischnewski N, et al. Prevalence of nosocomial infections in representative German hospitals. J Hosp Infect 1998;38:3749.

12. Schifman RB, Howanitz PJ. Nosocomial infections: a college of American pathologists Q-probes study in 512 North American institutions. Arch Pathol Lab Med 1994;118:115-119.

13. Horan TC, Gaynes RP, Martone WJ, Jarvis WR, Emori TG. CDC definitions of nosocomial surgical site infections, 1992: a modification of $\mathrm{CDC}$ definitions of surgical wound infections. Infect Control Hosp Epidemiol 1992;13:606-608.

14. Garner JS, Jarvis WR, Emori TG, Horan TC, Hughes JM. CDC definitions for nosocomial infections, 1988. Am J Infect Control 1988;16:128 140 .

15. Owens WD, Felts JA, Spitznagel EL. ASA physical status classifications: a study of consistency of ratings. Anesthesiology 1978;49:239243.

16. Altemeier WA, Burke JF, Pruitt BA, Sandusky WR. Manual on Control of Infection in Surgical Patients, ed. 2. Philadelphia: J. B. Lippincott; 1984.

17. Hox JJ. Applied Multilevel Analysis. Amsterdam: TT-Publikaties; 1995.

18. Greenland S, Rothman KJ. Fundamentals of epidemiologic data analysis. In: Rothman KJ, Greenland S, eds. Modern Epidemiology, ed. 2. Philadelphia: Lippincott-Raven; 1998:216-217.

19. Rice N, Leyland A. Multilevel models: applications to health data Journal of Health Services Research \& Policy 1996;1:154-164.

20. Khuri SF, Daley J, Henderson W, et al. Relation of surgical volume to outcome in eight common operations: results from the VA National Surgical Quality Improvement Program. Ann Surg 1999;230:414-432.

21. Schrag D, Cramer LD, Bach PB, Cohen AM, Warren JL, Begg CB. Influence of hospital procedure volume on outcomes following surgery for colon cancer. JAMA 2000;284:3028-3035.

22. Roohan PJ, Bickell NA, Baptiste MS, Therriault GD, Ferrara EP, Siu AL. Hospital volume differences and five-year survival from breast cancer. Am J Public Health 1998;88:454-457.

23. Bach PB, Cramer LD, Schrag D, Downey RJ, Gelfand SE, Begg CB. The influence of hospital volume on survival after resection for lung cancer. N Engl J Med 2001;345:181-188.

24. Laffel GL, Barnett AI, Finkelstein S, Kaye MP. The relation between experience and outcome in heart transplantation. N Engl J Med 1992; 327:1220-1225

25. Begg CB, Cramer LD, Hoskins WJ, Brennan MF. Impact of hospital volume on operative mortality for major cancer surgery. JAMA 1998;280:1747-1751.

26. Sosa JA, Bowman HM, Gordon TA, et al. Importance of hospital volume in the overall management of pancreatic cancer. Ann Surg 1998;228:429-438.

27. Hughes RG, Hunt SS, Luft HS. Effects of surgeon volume and hospital volume on quality of care in hospitals. Med Care 1987;25:489 503.

28. Geubbels ELPE, Nagelkerke NJD, Mintjes-de Groot AJ, Vandenbroucke-Grauls CMJE, Grobbee DE, de Boer AS. Reduced risk of surgical site infection through surveillance in a network. Submitted for publication. 


\section{APPENDIX}

ASSOCIATION OF HOSPITAL-RELATED DETERMINANTS AND SURGICAL-SITE INFECTION FOLLOWING HIP ARTHROPLASTIES FOR ORIGINAL MODELS AND MODELS INCLUDING POSTDISCHARGE SURVEILLANCE AS AN EXPLANATORY VARIABLE

\begin{tabular}{|c|c|c|c|c|}
\hline \multirow[b]{2}{*}{ Hospital-Related Determinant } & \multicolumn{2}{|c|}{$\begin{array}{l}\text { Adjusted Model } \\
\text { Without PDS }\end{array}$} & \multicolumn{2}{|c|}{$\begin{array}{l}\text { Adjusted Model } \\
\text { With PDS }\end{array}$} \\
\hline & $\mathbf{R R}$ & $\mathbf{C l}_{95}$ & $\mathbf{R R}$ & $\mathbf{C l}_{95}$ \\
\hline \multicolumn{5}{|l|}{ No. of beds } \\
\hline$<300$ & $1^{*}$ & & $1^{*}$ & \\
\hline 300 to 600 & 1.26 & $0.71-2.22^{\dagger}$ & 1.21 & $0.69-2.14^{\dagger}$ \\
\hline$>600$ & 0.78 & $0.40-1.51^{\dagger}$ & 0.72 & $0.36-1.46^{\dagger}$ \\
\hline Non-university affiliated & $1^{*}$ & & $1^{*}$ & \\
\hline University affiliated & 1.32 & $0.55-3.19^{\ddagger}$ & 1.22 & $0.49-3.01^{\ddagger}$ \\
\hline Non-teaching hospital & $1^{*}$ & & $1^{*}$ & \\
\hline Teaching hospital, residents allowed to operate without supervision & 0.60 & $0.23-1.54^{\ddagger}$ & 0.55 & $0.21-1.43^{\ddagger}$ \\
\hline Teaching hospital, residents not allowed to operate without supervision & 1.28 & $0.83-1.97^{\ddagger}$ & 1.21 & $0.77-1.89^{\ddagger}$ \\
\hline Annual volume of operations (per 50 operations) & 0.85 & $0.74-0.97^{\dagger}$ & 0.85 & $0.73-0.97^{\dagger}$ \\
\hline $\begin{array}{l}\text { Staff for nosocomial infection prevention and control (per full-time equivalent } \\
\text { employee per } 250 \text { beds) }\end{array}$ & 1.21 & $0.64-2.30^{\dagger}$ & 1.30 & $0.67-2.51^{\dagger}$ \\
\hline $\begin{array}{l}\text { Staff for prevention and control of SSIs (per full-time equivalent employee per } \\
250 \text { beds) }\end{array}$ & 0.48 & $0.16-1.44^{\dagger}$ & 0.49 & $0.17-1.45^{\dagger}$ \\
\hline No. of surgeons & 1.08 & $0.92-1.25^{\S}$ & 1.06 & $0.90-1.24^{\S}$ \\
\hline Median no. of years of surgeons' experience (per 5 y) & 0.98 & $0.79-1.21^{\dagger}$ & 0.98 & $0.79-1.22^{\dagger}$ \\
\hline \multicolumn{5}{|c|}{ 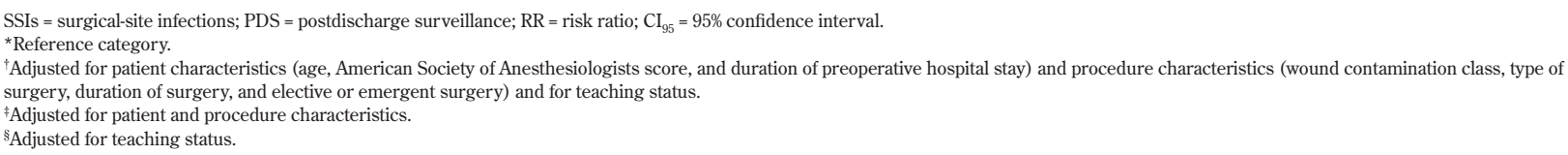 } \\
\hline
\end{tabular}

